\title{
Gaston Bachelard: uma pedagogia racional
}

Ângelo Márcio Macedo Gonçalves ${ }^{1}$

\section{Considerações iniciais}

O elemento fundamental da epistemologia de Bachelard é o de saber como o caráter inovador da ciência contemporânea proporciona a reflexão dos novos caminhos que esse saber assumiu na atualidade. O "novo espírito científico" que opera na atividade das ciências da natureza, produzida principalmente pelas mudanças ocorridas no interior das ciências físicas, exige que uma nova filosofia seja construída a partir da sistemática revolução nas noções de base do conhecimento científico, assim como sua transmissão. O nosso interesse será o de identificar relações das reflexões da epistemologia com a transmissão do saber científico e como é formulada uma noção de pedagogia racional.

Esse tema merece toda a insinuação que seu título reserva, simula ou, talvez, explicita. Muito embora, por trás da aparente fluidez semântica do tema e dos termos, a epistemologia e a relação com o ensino se nos apresenta em sentido bem específico; uma região sutil, que apesar da sutileza, é profícua no entendimento da questão. Podemos até achar que é inusitada, visto que a acuidade filosófica com seu temperamento sistêmico nos força a uma tentativa de categorização a partir de um campo de modalidades, que, não obstante a sua efetiva relevância no pensamento de Bachelard, não se revela, pois, tranquilamente.

O tema 'educação' não parece ter sido tratado explicitamente e diretamente por Bachelard. Ademais, é do campo do possível, extrair contribuições relevantes para a pedagogia ou o ensino de ciências e, desse modo, constituir um novo modelo de compreensão dessa prática, seus fundamentos e um novo modelo de ensino, de escola e, mais importante, de aprendizagem. Talvez até uma antropologia da escola dentro de categorias epistemológicas precisas, que Bachelard apresenta em sua obra.

Como dissemos, aparentemente, não há um tratamento explícito em Bachelard das

\footnotetext{
${ }^{1}$ Universidade Estadual de Feira de Santana (UEFS), Feira de Santa - BA, e-mail: angelomgoncalves@uol.com.br Periódico Horizontes - USF - Itatiba, SP - Brasil - e021049
} 
questões relativas à pedagogia. No entanto, em La formation de l'esprit scientifique, Le rationalisme apliqué e L'idealism discursif, com efeito, observamos uma preocupação relevante para o caráter de formação do sujeito na operação de produção de conceitos. Desta forma, o tema da educação, em sua obra, tem como elemento essencial - no qual nos deteremos e desenvolveremos nesse trabalho - , o rompimento com o conhecimento comum e com uma ciência estável ${ }^{2}$ e estruturada na experiência imediata.

\title{
Fundamentos da pedagogia racional
}

A pedagogia deve começar com uma mudança de cultura experimental e com a superação dos "obstáculos epistemológicos", que são os preconceitos e equívocos fixados na mentalidade corrente. Eis a 'lição' de Bachelard. No ensino elementar, as experiências muitos marcantes, cheias de imagens, são falsos centros de interesse. O professor deve passar continuamente da experiência para a abstração, evitando as imagens, as metáforas e as analogias, para fazer do ensino uma reorganização total do saber. É esse processo que chamaremos de pedagogia racional.

A proposta bachelardiana de uma nova pedagogia aparece na medida em que se admite um ensino assistemático, isto é, onde o trabalho educativo é fundamentalmente uma relação dialógica de construção de ideias e onde não se aprende pelo acúmulo de informações. Para aprender será necessário haver uma mudança de racionalidade, necessária para o aprendizado científico e para a compreensão do novo espírito científico. Nesse momento, o professor tem que promover a aprendizagem sem que haja a imposição do saber.

\begin{abstract}
A formação do espírito científico não é somente a reforma do conhecimento vulgar, mas ainda uma conversão dos interesses. Reside precisamente o princípio do engajamento científico. Demanda o abandono dos primeiros valores; é procura de interesses tão distantes, tão separados dos interesses usuais que se compreende seja tão prontamente desprezado por aqueles que tiram vantagens de engajamentos imediatos e que 'existem' a partir dos valores primeiros, nos valores que thes são primitivamente dados, seja do exterior, seja do interior (BACHELARD, 1998, p.24).
\end{abstract}

\footnotetext{
${ }^{2}$ No momento em que Bachelard escreve sua obra epistemológica, essa crítica inovadora vai contra uma "postura" positivista vigente entre os cientistas.
}

Periódico Horizontes - USF - Itatiba, SP - Brasil - e021049 
Com efeito, essa ruptura inicial com as ideias prévias é uma necessidade para a compreensão das teorias físicas do século XX; teorias que mostram a insuficiência dos fundamentos do realismo ingênuo, e apresentam a abstração como um procedimento normal e fecundo de desobstrução do espírito, dentro da compreensão do encadeamento dos eixos racionais.

Ideia prévias no processo de ensino-aprendizagem é uma questão importante em Bachelard. Basicamente o que entendemos por ideias prévias são os matizes adquiridos pela situação ordinária dos sujeitos. Quais sejam: os conhecimentos adquiridos na emergência cotidiana, nas informações da vida diária, na participação efetiva da cultura em geral. Aspectos religiosos, informações científicas, divulgações da mídia, a convivência social, além das heranças da tradição familiar. São exemplos do conteúdo adquirido na formação geral do indivíduo.

No primeiro momento, a ideia nova tem origem em um espírito solitário, para, em seguida, esta ideia ser inserida num processo discursivo e dialógico que vai corroborar sua coerência (BARBOSA; BULCÃO, 2004). Regulamente, nossas ideias aparecem como um conhecimento assistemático, e a fundamentação consistiriam na atividade de sistematização desses conteúdos. Esta tarefa seria uma organização das manifestações da existência humana, direcionadas para um resultado ativo. Para a organização das ações. Requeremos cautela nessa ideia, quando temos o que Bachelard propõe. Outro tipo de viés de conhecimento.

Para esse tipo de conhecimento, a pedagogia não deverá desenvolver-se na dependência de um continuísmo do conhecimento do senso comum e científico; o processo de ensinoaprendizagem não deve fundamentar-se somente em conhecimentos prévios, ele deve partir de racionalizações, deve formar espíritos dinâmicos. Logo, a educação tem que começar pela superação dos obstáculos: “O conhecimento é, assim, o resultado de um trabalho ativo, que diz respeito tanto ao objeto como também ao sujeito. Diante do objeto, o sujeito elimina as impressões espontâneas advindas desse primeiro contato e que impedem a construção objetiva" (BARBOSA; BULCÃO, 2004, p.51).

$\mathrm{O}$ ato de conhecer deve dar-se contra um conhecimento anterior. Esses obstáculos significam cristalizações dos conhecimentos prévios, que dificultam o processo de construção do novo conhecimento. Para Bachelard, “[...] a noção de obstáculo epistemológico pode ser 
estruturada tanto no desenvolvimento histórico do pensamento científico como na prática da educação. Nestes casos, não é um estudo cômodo. A história, em princípio, é hostil a todo julgamento normativo" (1999, p.17).

Quais os obstáculos e quais as suas estruturas são questões explícitas que Bachelard infere sobre a sua compreensão do ensino. No entanto, uma análise exaustiva dessa questão demandaria muito tempo, visto que é um texto extenso e, no nosso caso, extrapolaria o nosso objetivo aqui exposto.

O trabalho da epistemologia de Bachelard é o de promover uma escala de conceitos e demonstrar como cada conceito deu origem a outro. Para isso, deve-se estabelecer uma escala derivatória, que dá o significado do progresso dos conceitos do conhecimento científico. Na medida em que uma síntese é feita, quando se faz uma progressão psicológica dos conceitos, identifica-se uma eficácia epistemológica; em outras palavras, concebe-se um esforço de racionalidade de construção, que chega a um ponto extremo de tomar os fatos como ideias. Daí se segue que a educação é uma interpretação racional, numa regulação cognitivo-afetiva, que significa um trabalho constante de combate às ilusões solidificadas e adquire, com um esforço de retificação, a negação da sensação imediata.

Situação que chamamos de um estado abstrato ligado a uma conquista catártica; que ultrapassa os obstáculos epistemológicos, mostrando que a abstração é um dever, um dever científico (PERROT, 2005). Um conhecimento que não parta dessas sensações coloca a experiência antes e acima da crítica. Nesse momento, as imagens estão no lugar das ideias. Bachelard afirma que os livros de ciências do século XVIII tinham como ponto de partida a Natureza, e as ciências tinham um vínculo direto com a vida cotidiana. O leitor e o autor estavam no mesmo nível, e as ciências eram socializadas. Essa característica de socialização das ciências, em vez de trazer benefícios, traz obstáculos para a cultura científica e não oferece a descrição exata do fenômeno. Para Bachelard, o livro de ciências moderno deve apresentar que

[...] a ciência está ligada a uma teoria geral. Seu caráter orgânico é tão evidente que será difícil saltar os capítulos. Passadas as primeiras páginas, já não resta lugar para o senso comum; nem se ouve as perguntas do leitor. Amigo leitor será substituído pela severa advertência: preste atenção, aluno! O livro propõe perguntas. O livro comanda (BACHELARD, 1999, p.24). 


\section{Pedagogia e conceituação: do abstrato ao cognitivo ou a cognição do abstrato}

As habilidades cognitivas precisam ser cultivadas e estarem disponíveis antes de serem solicitadas. Para essa nova pedagogia, sendo cultivadas, e subsequentemente revistas, devem ser aplicadas no processo de aprendizagem. Nesse processo, esse tipo de cognição significa compreender como esses mesmos procedimentos são conectados às várias formas de compreensão. As habilidades cognitivas caracterizam-se pelas investigações estruturadas da acessibilidade e atração dos modelos de definição e conceituação. Essa nova pedagogia deverá romper com o paradigma de que os conceitos científicos tendem a apresentarem-se como inertes e imóveis. De outra forma, Bachelard insiste no caráter dinâmico desses conceitos e estabelece um processo de torná-los, por meio de critérios específicos e procedimentos de classificação, compreensíveis no seu movimento.

O método bachelardiano depende de um conjunto de proposições nada ingênuas acerca da natureza do pedagógico, isto é, depende de um conteúdo e de uma filosofia, que mais tarde ele chamará de racionalismo dialogado. Isso aparece em vários momentos de sua obra. Às vezes de forma subliminar e outras vezes mais explicitamente no corpo do texto. Ademais, o que ele pretende com essa metodologia exposta na composição de sua tese é o acesso ao abstrato. No livro La formation de l'esprit scientifique, 1938, sendo um trabalho que aparece como sua suposta obra 'pedagógica', tem um capítulo que acreditamos ser o mais direto para o que aqui nos interessa. O capítulo se intitula "Conhecimento geral como obstáculo ao conhecimento científico". É de bom tom relatar que esse 'conhecimento científico' faz parte do que ele chama de "o novo espírito científico", ou seja, na obra com o mesmo título, ele estabelece, assim como Comte, uma hierarquia do saber e a abstração científica é o terceiro estado desse novo espírito. Outros dois capítulos são fundamentais para entender essa relação da cognição do abstrato e do abstrato cognoscível, lição da sua pedagogia. Tem outros dois capítulos no Le rationalisme Apliqué, 1949, (Connaissance commune et connaissance scientifique et Le rationalisme enseignant et le rationalisme enseigné) et dans Le matérialisme rationnel, 1953, (la conclusion: connaissance commune et connaissance scientifique). Bachelard é um filósofo que inaugura um modo novo de discursividade.

A educação é formadora do sujeito. Ela procede a um trabalho de aventura racional. 
Não obstante, esse procedimento baseia-se numa ordem criteriosa e com uma exatidão metodológica. Admitamos que Bachelard não seja superficial. Há nessa perspectiva da educação racional, uma tentativa de clareamento e iluminação de controvérsias de conceitos. Não há uma fuga da excelência do pensamento; pelo contrário, é uma tentativa de pensar excelentemente disciplinas científicas, sem proporcionar, nesse trabalho, desvios, saltos ou dissimulações.

A pedagogia racional proposta por Bachelard critica a ideia de que a educação tem como base fundamental a necessidade de memorização e recordação das informações. Com efeito, a sua proposta de educação científica deve partir da introdução dos fundamentos e das condições do conhecimento abstrato e, em seguida, da sua efetivação: "O concreto se revela como uma promoção do abstrato, pois é o abstrato que fornece os eixos mais sólidos da concretização. A objetividade, assim elaborada, se dispõe em profundeza sob o fenômeno. O noumeno se multiplica e se mobiliza" (BACHELARD, 1970, p.5).

Esse trabalho educativo consiste na relação dialógica que conduz a uma construção das ideias. As respostas às perguntas não são previsíveis; no entanto é a partir da aplicação do pensamento que se consegue atingir a compreensão de uma ideia, assim como se consegue uma elaboração de uma nova racionalidade. Isso se caracteriza por uma mudança inerente ao aprendizado científico. É uma mudança descontínua, que não depende das noções remanescentes incrustadas nos hábitos intelectuais não questionadores. Deve-se adquirir uma nova cultura científica.

[...] Pouco importa a Bachelard a etiqueta que os amadores de classificações escolares ou os censores de ideologias heterodoxas procuram colar sobre o que não é seu sistema, mas somente uma linha de pensamento. Se for considerado idealista quando aborda a ciência pela via da física matemática, ele responde: Idealismo discursivo, isto é, laborioso em sua dialética e nunca triunfante sem vicissitudes (CANGUILHEM, 1972, p.52).

A aprendizagem não deve começar de forma contínua; de outro modo, ela deverá deformar um conhecimento para construir outro. $O$ aluno só deve apreender se lhe forem dadas as razões que obriguem à mudança da sua razão. Deve-se substituir um conhecimento estático por um conhecimento dinâmico. O professor tem que se desprender do dogmatismo do 
conhecimento e ir em direção oposta, isto é, impondo uma razão aberta. Cumpre ressaltar e acreditamos que isso já tenha ficado exposto na nossa argumentação, questão central do nosso trabalho -, que essa abertura não significa negligências ou conjecturas superficiais, pelo contrário, em Bachelard as afirmações justificam-se com um grande conhecimento de causa. O fato de propor uma "nova pedagogia", assim como foi necessário estabelecer uma lógica não clássica e um não-substancialismo, diz respeito às diferenças precisas entre o aprendizado de uma ciência que está diretamente ligada com o mundo sensível, com apoio em imagens imediatas, com uma ciência do mundo microfísico. As noções do mundo microfísico impõem restrições aos modelos de conhecimento do mundo macro, e essa composição de novas noções também modificam as maneiras e as forma de educação

A pedagogia racional exige que a educação seja constituída a partir dos problemas que suscitam o desenvolvimento de novas teorias científicas. Ela é construtiva. Ela constrói novos conhecimentos como ferramenta para o desenvolvimento do pensamento, tendo como prioridade a possibilidade de compreensão dos novos fatos científicos. Bachelard propõe uma pedagogia das noções científicas, isto é, uma expressão e dinamização do ensino. É aprender ensinando: “O racionalismo da ciência contemporânea é, pois docente e discente e se fundamenta numa atividade essencialmente pedagógica, na qual o ato de pensar e de refletir faz parte da própria dinâmica de formação e de educação" (BARBOSA; BULCÃO, 2004, p.51).

Concordamos plenamente com as autoras e gostaríamos de argumentar que essa atividade essencialmente pedagógica se faz em um exercício exaustivo de uma racionalidade comprometida com modelos abstratos, de forma que uma educação na relação com o desenvolvimento das ciências matemáticas, isto é, dos modelos das teorias físico-químicas matemáticas leva o sujeito a constituir o seu próprio eu formativo. O exercício de abstração, condição necessária da filosofia, deve ser transferido e aplicado para os modelos de ensino. É a abstração que tem que ser um elemento ou um componente de grande relevância para o ensino; não só a compreensão da aplicação, mas também a possibilidade da compreensão. A abstração como componente epistemológico é necessária para o ensino das ciências e uma das formas de adquirir isso é a superação dos obstáculos e a assunção do erro. Do diferente. 


\section{Um novo campo do saber}

Existem duas vertentes que são atribuídas a Bachelard. Uma científica (epistemológica) e outra poética. Mas, o que nos importa é o que muito bem pensou Lacroix (2008): como todos os pensadores dos melhores séculos, como Montaigne, Rabelais, Fénelon, Rousseau, Schopenhaurer, e Nietzsche, Bachelard é um éducateur. Identificamos no pensamento bachelardiano, em primeiro lugar, o estabelecimento e uma concepção de um novo campo de saber. Partindo de um novo racionalismo, um racionalismo aberto e prospector, constrói-se e estrutura uma organização dos pressupostos de base. Com a superação dos obstáculos, cria-se um novo campo de atuação racional e um novo modelo educacional. Entendemos como uma não-escolaridade do racionalismo em Bachelard e afirmamos que as pedagogias do fácil merecem suspeita, e esse tipo de modelo torna a ciência mais concreta e mais compatível com a prática humana. Todo esse malabarismo didático pode receber a rubrica bachelardiana de espírito escolar. A formação do novo espírito científico se opõe radicalmente a tal tendência para o agradável e o fácil. Contudo, será necessário não confundir o que se chama de racionalismo não-escolar com o caráter "estudantil" do ensino. O primeiro diz respeito a uma pedagogia baseada no conhecimento a partir de ideias prévias; no segundo, significa que o ato de ensinar é uma forma de estudo e que a forma de ensinar é um exercício de avaliação de conceitos. Portanto, a ação do pensamento e da reflexão é a dinâmica específica e a essência da pedagogia, assim como é a estrutura da educação.

Para o ensino de ciências pressupõe-se uma concepção prévia de ciência por parte do professor. Para Bachelard, uma concepção de uma nova ciência proporciona rupturas com uma concepção tradicional. Ele estabelece alguns axiomas para o ensino de ciências e afirma que será um esforço muito grande adquirir esse novo formato. A superação dos obstáculos epistemológicos e a compreensão do novo campo do saber é o ponto de partida para o ensino; não obstante, a compreensão desta natureza inicial do ensino é o processo da nova pedagogia que contribui para a formação do professor de ciência, demostrando a importância dos aspectos filosóficos (racionais) da educação. Esses axiomas seriam: 1) o processo de ensino é uma reconstrução de o próprio saber; 2) só os eixos racionais permitem essa reconstrução e 3) ensinar ciência é saber formular problemas. Somente os livros e ações com alguma coisa de novo produzem um algo novo (DELEUZE; GUATARRI, 1995). 
O ato de ensinar requer uma reconstrução da própria concepção de ciência. As mudanças ocorridas nas ciências contemporâneas modificam os padrões cognitivos do próprio conhecimento e, consequentemente, a transmissão desse conhecimento sofre também modificações na sua estrutura, visto que o ensino tem uma dependência com uma concepção correspondente. Portanto, o ensino, para Bachelard, acompanha o novo espírito científico, isto é, por ter, as ciências contemporâneas um alto grau de abstração nas suas teorias, o seu ensino deverá acompanhar, também, essa forma científica:

Assim, torna-se tão difícil aprender química sem a compreender como receita de cor, sem esses pequenos tropeços que nunca enganam o professor perspicaz, a lição de matemática. E se confiarem assim tanto nesse poder de memorização, bastar-vos-á abrir o manual de Dewar - ou o de Paulmann - ou o de Eistler - ou o de Bernard e Albert Paulmann - para porem à prova as vossas forças. Abordai a química difícil e reconhecereis que entrastes num reino novo de racionalidade (TERNES, 1995, p.88).

Nessa nova pedagogia, o professor deve renunciar o papel de autoridade da informação e assumir a função de autoridade de instrução. Ele deve assumir a responsabilidade de estabelecer as condições que guiarão os alunos para uma formação discursiva, mais produtiva e autocorretiva. Explorar-se-ia com esses planos de discussão apropriados, exercícios de clarificação de conceitos e sua devida exploração interna. E é através da história das ciências que, segundo Bachelard, essa função pedagógica pode ser instaurada. "[...] é preciso que demos atenção à transmissão da ciência de uma geração para outra, à formação do espírito científico, à profunda inscrição do pensamento científico na psique humana" (BACHELARD, 1999, p.85).

Essa função da história das ciências constitui uma questão que é a de saber em que forma e sob que condições, existem uma ação positiva sobre o pensamento científico contemporâneo e a sua transmissão. Para Bachelard, o eixo central da problemática significa que a direção é dada no sentido de uma compreensão melhorada. A história das ciências é uma teia de juízos internos sobre os valores do pensamento e das descobertas científicas, e o traçado das linhas de progresso significa o das ligações racionais do saber. Para julgar o passado, teremos que conhecer o presente. Portanto, a transmissão da ciência é um exercício de fazer compreender a multiplicidade das dificuldades que entravam o progresso. 


\section{Considerações finais}

Como se configura o problema fundamental da pedagogia da razão, a partir da obra bachelardiana? O "problema pedagógico" significa que quanto mais breve for o processo de identificação das ideias, mais fraco será o pensamento experimental. Desta forma, os esquemas de explicação devem seguir o caminho que proporcione a diluição das imagens ingênuas. As ideias prévias prejudicam a racionalidade. Para Bachelard, a condição para se chegar a uma teoria da abstração científica é psicanalizar o conhecimento objetivo e examinar com cuidado todas as seduções e persuasões das facilidades das ideias prévias. Para ele, a pedagogia corrente falha, visto que sempre se deixa seduzir pelas generalidades do conhecimento.

A formação do professor de ciências, para Bachelard, é uma tarefa complexa, assim como a delimitação do processo de ensino-aprendizagem. A formação do professor deve ultrapassar a questão ideológica da educação. O educador deve definir a importância epistemológica para uma evolução do conhecimento. Ele deve ter como referencial as dimensões históricas, lógicas e simbólicas, que são instrumentos de leitura do real e formalização do objeto para reverter a situação da educação. A tarefa do educador é, por um lado, fazer uma psicanálise do conhecimento objetivo, psicanalizar o interesse derrubando o utilitarismo e, por outro lado, ele deve procurar defender o aluno da massa de efetividade, isto é, sair do natural para o humano e da simples representação para a abstração, formando assim a condição necessária para a constituição e construção do conhecimento.

A pedagogia racional de Bachelard é essencialmente uma pedagogia erudita. A escola deve ter o que Ihe tomaram: sua função, que é estudar. Enfim, a epistemologia de Bachelard é responsável por promover esse aspecto de uma formação científica intelectual capaz de levar o estudante a um profundo exercício de pensamento e a compreensão e apropriação do novo espírito científico. Essa pedagogia é necessária para a compreensão das noções científicas contemporâneas.

\section{Referências}

BACHELARD, G. L'idéalism discursif. In: BACHELARD, G. Études. Paris; Vrin, 1970. p.77-86. 
BACHELARD, G. Le rationalisme appliqué. 3 éd. Paris: Quadrige/PUF, 1998.

BACHELARD, G. La formation de l'esprit scientifique: contribution à une psychanalyse de la connaissance. Paris: Vrin, 1999.

BARBOSA, E.; BULCÃO, M. Bachelard: pedagogia da razão, pedagogia da imaginação.

Petrópolis, RJ: 2004.

CANGUILHEM, G. Sobre uma epistemologia concordatária. Tempo Brasileiro, n.28, p.11-23, jan.-mar. 1972

DELEUZE, G.; GUATTARI, F. Mil Platôs: capitalismo e esquizofrenia, vol. 1. Rio de Janeiro: Ed. 34, 1995.

LACROIX, J. Le rationalisme aplique de Gaston Bachelard. Association des Amis de Gaston Bachelard, Dijon, Bulletin n.10, p.6-15, 2008.

PERROT, M. Bachelard et la notion de métaphysique concrète. In: BULCÃO, M. (org.).

Bachelard: razão e imaginação. Feira de Santana: Universidade Estadual de Feira de Santana, 2005, p.135-148.

TERNES, J. Bachelard: um racionalismo não-escolar. Reflexão: Colóquio Bachelard, Campinas: UNICAMP. ano XX, n.62, p.7-14, 1995. 